\title{
Selective attention and complex discrimination learning in the Japanese quail (Coturnix coturnix japonica)'
}

\author{
FREDERICK G. FIDURA, Michigan State \\ University, ${ }^{2}$ East Lansing, Mich. 48823
}

This study compared (a) the ability of Japanese quail (Coturnix coturnix japonica) to learn a complex visual discrimination, where either color, pattern, or form was relevant and the remaining two dimensions were irrelevant, to (b) the learning of these dimensions presented alone. In a second experiment, transfer tests were administered in order to assess any incidental learning of the irrelevant stimulus dimensions. The results showed that (a) adding irrelevant cues of greater salience retarded learning, while adding cues of less salience had no effect, and $(b)$ incidental learning of the less salient irrelevant dimensions occurred, but not for the most salient irrelevant dimen. sion.

The following two experiments were intended to assess, with Japanese quail, (1) the acquisition of a complex simultaneous visual discrimination in which the complex discriminative stimulus was composed of three independent binary stimulus dimensions with only one dimension relevant, and (b) what is learned about irrelevant stimulus dimensions during the course of complex discrimination training.

\section{EXPERIMENT 1 Subjects}

The Ss were 54 male and female Japanese quail (Coturnix coturnix japonica) 50-60 days of age.

\section{Apparatus}

The apparatus consisted of an automated commercial operant chamber fitted with two pecking keys. The chamber was modified by raising the floor $2-1 / 8$ in. and by mounting a multiple stimulus projector behind each key.

Procedure

The Ss were maintained at $75-80 \%$ ad lib body weight. A pecking response was well established by requiring the Ss to peck an amber-lighted key vs a simultaneously present nonlighted key (randomized for position) for 200 food reinforcements. This was done to overcome the birds' natural tendency to perseverate on one key. Previous research (Fidura \& Gray, 1966) has shown that pretraining with amber as compared with white has no effect on a later-learned red-green color discrimination.
Following these 200 pretraining trials, 27 Ss were randomly assigned to the simple discrimination group, the remaining $27 \mathrm{Ss}$ were assigned to the complex discrimination group. Within each group, three subgroups of nine Ss each learned either a color, pattern, or form discrimination. The simple discrimination subgroups learned one of the following discriminations presented alone:

\begin{tabular}{|c|c|}
\hline Dimension & Binary Stimulus Attributes \\
\hline & \\
\hline $\begin{array}{l}\text { Pattern } \\
\text { Form }\end{array}$ & $\begin{array}{l}\text { horizontal vs vertical white lin } \\
\text { white triangle vs white circle }\end{array}$ \\
\hline
\end{tabular}

The attribute listed first was positive. Color attributes were equated for intensity, and position was randomized for the attributes of each dimension.

The three complex discrimination subgroups learned to discriminate one relevant dimension in the presence of two binary dimensions which were irrelevant and varied independently of the relevant dimension.

Visually, the keys appeared as a white triangle or circle on a red or green background with four white horizontal or vertical lines superimposed on the other two dimensions. The eight ways of presenting the three dimensions were randomized and thus each of the dimensions was independent of the others and was randomized for position. As in the above list, the attribute listed first was positive when that dimension was relevant.

For all Ss, a response to either key terminated the stimulus lights and rendered the keys inoperative for $8 \mathrm{sec}$. A frod hopper was available for $5 \mathrm{sec}$ following a correct response. To avoid perseveration on one key, on error trials the stimulus sequencing system was not advanced, consequently, the attributes maintained the

\section{Table 1}

Means and Standard Deviations of Total Trials to the First Criterion Trial for each Relevant Dimension and Degree of Complexity

\begin{tabular}{llllll} 
& & \multicolumn{4}{c}{ Relevant dimension } \\
\hline & & Color & Pattern & Form & Marginal \\
\cline { 3 - 6 } Complex & Mean & 21.9 & 412.4 & 1361.4 & 598.6 \\
Discrimination & SD & 22.9 & 164.0 & 647.5 & \\
\hline Simple & Mean & 34.9 & 114.4 & 329.1 & 139.5 \\
Discrimination & SD & 25.9 & 71.9 & 205.3 & \\
\hline Marginal & Mean & 28.5 & 242.7 & 835.8 & 369.0 \\
\hline
\end{tabular}

same relative position on the next trial Error and total responses to criterion were recorded. The criterion of acquisition was 15 consecutive correct responses. Experimental sessions ran an hour a day for each $S$.

Results and Discussion

Means and standard deviations of total trials to criterion (excluding the 15 criterion trials) for each relevant dimension and degree of complexity are presented in Table 1. A two-way analysis of variance of the data presented in Table 1 showed a significant effect for the relevant dimension variable $(F=40.4, \mathrm{df}=2 / 48, \mathrm{p}<.001)$ and the degree of complexity variable $(F=36.5$, $\mathrm{df}=1 / 48, \mathrm{p}<.001)$. The Relevant Dimension by Degree of Complexity interaction was also significant $(F=17.0, \mathrm{df}=2 / 48$, $p<.001$ ). The results of posteriori comparisons (Winer, 1962, p. 209) showed no significant difference $(p>.25)$ between the color-simple and color-complex subgroups. Significant differences $(\mathrm{p}<.001)$ were found, however, between the simple and complex discriminations when pattern or form were relevant.

These data suggest that for the Japanese quail, color discriminations are most easily learned, followed by pattern, then form, for both simple and complex discriminations. In general, these findings agree with the results of other studies of diurnal birds such as Cumming (1968), and others, concerning the relative difficulty of the stimuli used.

Differences in the acquisition measure suggest an innate distinctiveness hierarchy in Japanese quail, i.e., color stimuli are innately more salient followed by pattern stimuli which are less salient and finally, geometric form. Such a conclusion agrees with the position of Baron (1965) and Johnson \& Cumming (1968) that stimulus dimensions can be ordered into an attentional hierarchy. The data also imply that the addition of two irrelevant stimulus dimensions results in slower discrimination of the relevant dimension. However, the presence of a significant interaction suggests that any effects of complexity depend on the dimensions involved. In terms of an attentional hierarchy, these data suggest that if the relevant dimension is highly those of Zeigler (1963), Johnson \&

Note: $N=9$ per cell 
Table 2

Means and Standard Deviations of Total Trials to the First Criterion Trial for the Three Dimensions Presented Alone on the Posttraining Transfer Tests and from Experiment 1.

\begin{tabular}{|c|c|c|c|c|}
\hline & & Color & Pattern & Form \\
\hline $\begin{array}{l}\text { Posttraining transfer } \\
\text { (Experiment 2) }\end{array}$ & $\begin{array}{l}\text { Mean } \\
\text { SD } \\
\mathrm{N}\end{array}$ & $\begin{array}{l}35.2 \\
25.3 \\
18 \\
\end{array}$ & $\begin{array}{l}66.6 \\
35.3 \\
18 \\
\end{array}$ & $\begin{array}{c}155.0 \\
82.2 \\
18 \\
\end{array}$ \\
\hline $\begin{array}{l}\text { Simple } \\
\text { Discrimination } \\
\text { (Experiment 1) }\end{array}$ & $\begin{array}{l}\text { Mean } \\
\mathrm{SD} \\
\mathrm{N}\end{array}$ & $\begin{array}{c}34.9 \\
25.9 \\
9\end{array}$ & $\begin{array}{c}114.4 \\
71.9 \\
9 \\
\end{array}$ & $\begin{array}{c}329.1 \\
205.3 \\
9\end{array}$ \\
\hline $\begin{array}{l}t(d f=25) \\
p=\end{array}$ & & $\begin{array}{l}.001 \\
.92 \\
\end{array}$ & $\begin{array}{r}2.61 \\
.01\end{array}$ & $\begin{array}{l}3.41 \\
.005\end{array}$ \\
\hline
\end{tabular}

salient, then adding irrelevant dimensions of less salience has no effect. Thus, the learning of the color discrimination was not effected by the addition of the other less salient dimensions. For the pattern and form dimensions, just the opposite was true.

\section{EXPERIMENT 2}

Procedure

The three subgroups of nine Ss each, which were trained on a complex discrimination in Experiment 1 with either color, pattern, or form relevant, were given transfer tests by being required to learn a simple discrimination for each of the two previously irrelevant dimensions. Only one dimension was present throughout a discrimination problem and again thecriterion was 15 consecutive correct responses. The order in which these two discrimination problems were learned was randomly determined. Other procedural aspects were the same as in Experiment 1.

Results and Discussion

Means and standard deviations of trials to criterion (excluding the 15 criterion trials) for each of the dimensions are presented in the first row of Table 2 . Row 2 of Table 2 gives the comparable data for the simple discrimination subgroups of Experiment 1. The simple discrimination subgroups from Experiment 1 provided a control group against which transfer effects might be measured in Experiment 2. Also given are $t$ values and probabilities associated with the differences between the means of the posttraining transfer Ss and simple discrimination $\mathrm{Ss}$ for each dimension. On the form and pattern dimensions, Table 2 shows that significantly fewer trials were required to learn these dimensions by Ss for whom these dimensions were previously irrelevant in the complex task than for Ss which did not have such experience. That is to say, positive transfer occurred for the less salient dimensions. In the case of the color dimension, on the other hand, no significant difference was found. Also, it is clear from the results of the three $t$ tests taken together that an interaction exists between these positive transfer effects and the three stimulus dimensions. These positive transfer effects strongly indicate that something is learned about irrelevant dimensions during the course of complex discrimination training. However, the evidence of an interaction suggests that transfer only occurs with less salient stimuli (pattern and

Table 3

Means and Standard Deviations of Total Trials to the First Criterion Trial of the Pattern and Test as a Function of the Relevant Dimension in Experiment 1.

Simple dimension learned during post training transfer test

\begin{tabular}{lllr}
\hline $\begin{array}{l}\text { Dimension relevant during } \\
\text { complex discrimination } \\
\text { learning }\end{array}$ & & \\
\hline Color & Mean & 70.7 & 137.1 \\
& SD & 32.5 & 46.3 \\
\hline Pattern & Mean & & 172.1 \\
& SD & & 107.5 \\
\hline Form & Mean & 62.4 & \\
\hline $\mathrm{t}$ & SD & 39.4 & \\
$\mathrm{p}=$ & & .47 & 1.05 \\
& & .35 & .15
\end{tabular}
Form Dimensions from Posttraining Transfer form) and not for the most salient (color).

Where positive transfer was found, it might be expected that the greater the number of trials on which the irrelevant stimuli were presented, the greater the amount of transfer that should occur Table 3 presents means and standard deviations of trials to criterion for those $S$ s that learned the pattern and form discrininations in this experiment categorized by the dimension previously relevant during complex discrimination training. No significant differences were found for either pattern or form as a function of the dimension relevant during complex discrimination training.

As the data in Table 3 shows, there were no significant differences for pattern as a function of whether color or form was the previously relevant dimension. Such being the case, it also appears that whatever was learned about pattern during complex discrimination training was learned during the first 22 trials.

\section{REFERENCES}

BARON, M. R. The stimulus, stimulus control and stimulus generalization. In D. I. Mostofsky (Ed.), Stimulus generalization. Stanford, California: Stanford University Press, 1965. Pp. 62-71.

FIDURA, F. G., \& GRAY, J. A. Visual discrimination of color, pattern, and form in the Japanese quail (Coturnix cotumix japonica). Psychonomic Science, 1966, 5, 427-428.

JOHNSON, D. F., \& CUMMING, W. W. Some determiners of attention. Journal of the Fxperimental Analysis of Behavior, 1968, 11, $157-166$

WINER, B. J. Statistical principles in experimental design. New York: McGraw-Hill, 1962.

ZEIGLER, H. P. Effects on endbrain lesions on visual discrimination learning in pigeons. Journal of Comparative Neurology, 1963, 120 161-181.

\section{NOTES}

1. Portions of this paper were read at the 1967 meeting of the Midwestern Psychological Association. This report is based on a dissertation submitted to the Graduate School of Michigan State University in partial fulfillment of the requirements for the $\mathrm{PhD}$. The author is indebted to $M$. Ray Denny, Chairman of the dissertation committee, and also the committee members, $P$. Bakan, G. I. Hatton, and S. C. Ratner.

2. Now at State University of New Y ork, College at Geneseo. 